\title{
The Effect of the Keyword Method and Word-list Method Instruction on ESP Vocabulary Learning
}

\author{
Ana Piribabadi \\ Islamic Azad University, Takestan Branch, Iran \\ Ramin Rahmany \\ Islamic Azad University, Takestan Branch, Iran
}

\begin{abstract}
The present study examined the effect of the keyword method and word-list method instruction on ESP vocabulary learning across proficiency levels. Two groups of students at Islamic Azad University of South Tehran branch were selected with the total population of 120 Industrial engineering intermediate students with an average age of 21 . The students of each class were divided into two different homogeneous groups, the upper-intermediate level and the lower- intermediate level, based on their scores on the Oxford Placement Test. Each class was instructed through a specified method of vocabulary learning, i.e. the keyword method and word-list method, for an equal time of four weeks. Following both treatments, a multiple-choice test was administered to each class as the post-test to find out the ESP students' vocabulary knowledge. The results of the study indicated that the upper-intermediate learners who received the keyword method instruction outperformed the upper-intermediate learners who received the word-list method. In addition, the lowerintermediate level students in the keyword method group had better performance than those in the word-list method. Moreover, regardless of the proficiency level of the students, all of the students in the keyword method group obtained higher scores than those in the word-list method group. The results of the study revealed that the keyword method instruction has superiority over the word-lists method in learning ESP vocabulary regarding the proficiency level of the students.
\end{abstract}

Index Terms - keyword method, word-list method, ESP vocabulary

\section{INTRODUCTION}

In second language acquisition, vocabulary is an essential element in the four skills of speaking, listening, reading and writing. In order to communicate well in a foreign language, students should know a sufficient number of words and be familiar with how to use them correctly (Tabatabaei \& Hossainzadeh Hejazi, 2011).

However, this endless number of words may discourage many students who do not know how to memorize them rapidly. "ESP learners also experience the same problem because they learn English as a means to achieve their subjectspecific and ultimately their occupational goals both receptively and productively in their field of study" (Akbari, 2011, p. 7). The specialized words that ESP learners use are made up of words that occur frequently in a specialized text or subject area, but do not occur or are of very low frequency in other fields (Chung \& Nation, 2004).

Deciding about and selecting the methods to memorize and then internalize the words is the most important step in learning vocabularies (Amiryousefi \& Ketabi, 2011). In deciding which vocabulary-learning strategies should be recommended to EFL learners, teachers should consider factors that include L1, their motivation and purposes for learning the L2, the task and text being used, the nature of the L2 itself and learners' proficiency level (Schmitt, 2007).

According to Schmitt (2007), "vocabulary-learning strategy is an approach, which facilitates vocabulary learning and has attracted considerable attention. Strategies can help learners both in discovering the meaning of a word, and consolidating it, and are especially needed when students are encouraged to learn" (Amiryousefi \& Ketabi, 2011, p. 178).

Among all of the vocabulary-learning strategies, one of the best and most effective strategies in improving both immediate and delayed retention of second language vocabulary is the keyword method (Atkinson \& Raugh, 1975). In this method, learners work to make a link system, also called the "Chain system". The items are linked together to form a chain of associations. They allow the storage of information in memory in a way that it will be able to find it and get it back out when necessary (Higbee, 2007).

According to Baleghizadeh \& Ashoori (2010, p. 252) "two stages are involved in this strategy: first, a connection based on acoustic similarities is made between a new word and a familiar word (keyword) and second, an imaginable link that associates the target word and the keyword together is made".

On the other hand, the word-list method, also called list learning, is one of the old-fashioned vocabulary learning strategies, which needs more rehearsal. It consists of a sheet of paper on which learners write both the target word and its meaning. "Both teachers and learners can generate the strategy; however, the words are learned out of context and the main emphasis is on repetition and memorization, not meaningful learning" (Baleghizadeh \& Ashoori, 2010, p. 252). 
As many foreign language learners claim that the major obstacle in learning a new language is learning the vocabulary of that language not the structure, the aim of this study is to investigate the comparative effect of the keyword method and word-list method instruction on ESP vocabulary learning across two lower-intermediate and two upper-intermediate proficiency groups.

Regarding the foregoing discussion, the purpose of this study is to answer the following research question:

Is there any significant difference between the effectiveness of the keyword method and the word-list method instruction on ESP vocabulary learning across different proficiency levels?

\section{REVIEW OF LITERATURE}

Atay and Ozbulgan (2007) believe that successful vocabulary learners are considered as active strategy users who are aware of their own learning and try to maintain it, whereas poor learners do not have enough information about how to use various strategies to learn new words or connect the new words to their previous knowledge.

In this regard, many studies have been conducted on the effectiveness of the keyword method and word-list method instruction alone or in comparison to the other methods of vocabulary learning and many different findings about the usefulness of this method have been emerged.

Some researchers (Amiryousefi and Ketabi; 2011, Atay and Ozbulgan; 2007, Baleghizadeh and Ashoori; 2010, Tabatabaei and Hossainzadeh Hejazi; 2011) believed on the superiority of the keyword method to the other methods of vocabulary learning and stated that the keyword method can improve vocabulary learning.

The majority of the students prefer a course that engages them in the learning process because they feel satisfied with methods that reduce their stress of vocabulary learning. The keyword method helps learners to learn better and faster, have longer and better retention and change teacher-centred classrooms to student-centred ones (Ashoori, 2012).

In this regard, "keyword method is a useful way for enhancing vocabulary learning because the keyword method provided a meaningful visual image upon which to base memory for a new word's meaning" (Tabatabaei and Hossainzadeh Hejazi, 2011, p.273).

Jenpattarakul (2012) believed that using the keyword method instruction had three positive effects on the students: first, the students could store and retrieve a new set of vocabularies, and second it expanded and enhanced the students' imagination and creativity. It means that the more imagination and creativity the students had, the better they could memorize vocabulary. Third, students' motivation to learn English vocabularies increased because motivation could improve the students' proficiency level. Using the keyword method in the classroom can help students to retain the words in their long-term memory and store them easily.

According to Lin and Cheng (2008), applying the keyword method instruction caused a strong link between the target words and their definitions and positively affected the processing of meaning in memory. It seems that the keyword method produced greater learning effects than other semantic based or controlled learning conditions. Moreover, the keyword method is easily adaptable to foreign and second language classroom situation.

Richmond, Cummings and Klapp (2008) believed that mnemonic instruction should be expanded to other fields of study especially when instructional objectives require the acquisition and retention of science vocabulary and facts.

Not in line with the results of Atkinson and Rough (1975), who believed that the keyword method is good for beginners, Taguchi (2006) found that using the keyword method facilitates learning of older and experienced learners and improved only the productive rather than the receptive mode of learning.

Ashoori (2012) compared the effects of the keyword, context and word-list method instruction on long-term vocabulary recall of elementary female students and reached to the conclusion that the students in the keyword group instruction had better performance than the students in the other two groups on both cued-recall and word-recall tests. This study confirmed the powerful impact of the keyword method instruction on the learners' memory in recalling newly learned vocabulary items because of three reasons. First, according to the dual-coding theory, two complementary systems of storage, a semantic or verbal system, an image-based system, and the received information existing in the brain are processed in two distinct and interactive ways. Since in the keyword method, information is provided through two channels (visual and verbal), it yields superior retention compared to semantic-context technique, which provides information just through the verbal channel. The second reason is related to the remembering and selfconsciousness of learners during the learning process. In comparing the context group to the keyword method group, it is stated that advanced level learners are able to use the context method more than the elementary and intermediate level learners.

In comparing keyword method to word-list method, Rashidi and Sajjadi (2010) also reached the conclusion that, "the keyword method facilitates literal recall of new vocabulary definitions at the expense of the ability to use the vocabulary in any different context" (p. 64). Moreover, in line with the results of Hauptmann (2004), who believed that keyword method facilitates learning of both abstract and concrete words, the researchers stated that students who learn vocabulary through the keyword method instruction are better able to use new words even if these words are abstract. It means, "The students do not bother themselves memorizing long lists of vocabularies and do not forget the words as soon as they put the list away" (p. 64).

Khosravizadeh and Gerami (2011) believed that the younger the one was, the more words the one could recall with the help of word-list method instruction. In other words, becoming older affects the degree of recall. 
Baleghizadeh and Ashoori (2011) stated that using word-list method may result in some problems of attention. "It may be the case that some words may receive more attention compared to the other words in the list due to their particular positions. Nevertheless, there is no evidence of the existence of such a problem in learning with other methods since they tend to be more flexible" (p. 7).

According to Hayati Samian and Tavakoli (2012) rote-learning strategy was the most frequently used strategy among Iranian EFL learners. In addition, there is a direct relationship between the proficiency level of the students and rote learning strategy use. It means that the high-proficiency level students tend to considered rote learning strategies just as one of the ways of learning vocabulary, and low-proficiency level students tend to use rote learning strategies as the best and the most fundamental strategy.

In addition, Yang and Dai (2012) stated that "students prefer to engage in the vocabulary learning strategies that would be most appealing to them and that would entail less manipulation of the language" (p. 208). It means that learning words in a mechanical fashion is more time consuming and leads to faster forgetting. In addition, roterepetition, as a traditional way of vocabulary-learning strategies, is still favoured by many language learners, especially those at the initial and intermediate stages. Association, as one of the most useful strategies for vocabulary learning is frequently used by language learners in their attempts to commit words to long-term memory" (pp. 211\& 209).

Nevertheless, in recent years, few studies have been conducted on the comparative effect of the keyword method and word-list method on the retention of ESP vocabulary learning, especially concerning the proficiency level of the students. Thus, the present study aimed to fill this gap in the literature.

\section{METHOD}

\section{a) Participants}

120 intermediate industrial engineering learners were selected randomly from two classes of Islamic Azad University of South Tehran branch, Iran. In each class, the participants were divided into two different groups by means of Oxford placement test: the lower-intermediate group and the upper-intermediate group. In each class, the thirty students who obtained the top scores of this test made up the upper-intermediate level group. The lower-intermediate level group consisted of the other thirty students who obtained the lowest test-scores of the class. All of the participants had the same educational and language background.

\section{b) Instruments}

The instruments used in this study were questionnaires and tests. The questionnaire was used to elicit the demographical details from the participants. The questions on this questionnaire included the items about the gender, age and the educational and language background of the participants. In addition, questions about the way and strategies of memorizing the vocabularies were also included.

The tests, used in this study, comprised two separate sections: one pre-test and one post-test. The first part of the test was the proficiency test (placement test) which was used to make a distinction between the students' mastery of vocabulary knowledge in English and the second part was the multiple-choice vocabulary test which was used to investigate the effects of both treatments at the end of the study.

\section{c) Teaching Materials}

Thirty-two vocabulary items were selected from the content of English for the students of Industrial Engineering, book III: Industrial system analysis, written by Dr. Mohammad Fallahi Moghimi, as a teaching material. These vocabulary items including four lists of eight ESP words and each vocabulary list was taught in each teaching session (Appendix E).

The difficulty levels of these vocabulary lists were checked with a few experts and were controlled for several times. These vocabulary lists were arranged from simple to difficult based on the order of the chapters of the English for the students of Industrial Engineering, book III: Industrial system analysis.

\section{d) Procedure}

The study was conducted on two ESP classes of Islamic Azad University of South Tehran Branch. Based on the scores of the students on the Oxford Placement Test in each class, the students were divided into lower-intermediate level group and the upper-intermediate level group. After that, the whole population of each class, regardless of their proficiency levels, received two different treatments for four weeks.

In the first class, the students learned ESP vocabularies through the keyword method instruction and in the second class, the students learned ESP vocabularies through the word-list method instruction. Then, the post-test was administered.

\section{RESULTS AND ANALYSIS}

In order to answer the research question of this study, which addressed the effect of the keyword method and wordlist method instruction on ESP students' vocabulary learning regarding their proficiency levels, a two-way ANOVA was applied. The results of two-way ANOVA were summarized in Table 1. 
TABLE 1.

THE DESCRIPTIVE STATISTICS OF THE STUDENTS' SCORES

\begin{tabular}{|c|c|c|c|c|}
\hline High/Low Proficiency & Keyword/Word list & Mean & Std. Deviation & $\mathrm{N}$ \\
\hline \multirow[t]{3}{*}{ upper-intermediate } & Keyword Method & 19.80 & .407 & 30 \\
\hline & Word list Method & 17.43 & .679 & 30 \\
\hline & Total & 18.62 & 1.316 & 60 \\
\hline \multirow[t]{3}{*}{ Lower-intermediate } & Keyword Method & 18.67 & .479 & 30 \\
\hline & Word list Method & 15.07 & .868 & 30 \\
\hline & Total & 16.87 & 1.944 & 60 \\
\hline \multirow[t]{3}{*}{ Total } & Keyword Method & 19.23 & .722 & 60 \\
\hline & Word list Method & 16.25 & 1.422 & 60 \\
\hline & Total & 17.74 & 1.872 & 120 \\
\hline
\end{tabular}

According to the results of Table 1, there is a statistical difference between the mean scores and standard deviations of the upper-intermediate students in the keyword method and word-list method group. The upper-intermediate students who received the keyword method instruction got higher mean scores than the upper-intermediate students who received the word-list method instruction. It means that the upper-intermediate students in the keyword method group, with the mean of 19.80 and standard deviation of the 0.407 , had better performance than those in the word-list method class, with the mean of 17.43 and standard deviation of the 0.679 .

In the case of the lower-intermediate groups, the results of Table 1 show that the mean scores and standard deviation of students in the keyword method and word-list method instructions are different. That is to say, the students who received the keyword method instruction had reached higher mean scores than the students who received the word-list method instruction. It means that the lower-intermediate students in the keyword method group, with the mean of 18.67 and standard deviation of the 0.479 , had better performance than those in the word-list method instruction, with the mean of 15.07 and standard deviation of the 0.868 .

Regardless of the proficiency level of the students, Table 1 indicates that the students in the keyword method group instruction, with the mean scores of 19.23 and standard deviation of the 0.722 , had better performance than those in the word-list method group instruction, with the mean of 16.25 and standard deviation of the 1.422. It means that there is a difference between the mean scores and standard deviations of the students in the keyword method and word-list method group students.

In addition, the following results of the two-way ANOVA, which are summarized in Table 2, indicate that the observed mean differences are statistically significant.

TABLE 2.

THE RESULTS OF THE TWO-WAY ANOVA

\begin{tabular}{|c|c|c|c|c|c|c|}
\hline Source & Type III Sum of Squares & df & Mean Square & $\mathrm{F}$ & Sig. & Partial Eta Squared \\
\hline Corrected Model & $370.292^{\mathrm{a}}$ & 3 & 123.431 & $3.066 \mathrm{E} 2$ & .000 & .888 \\
\hline Intercept & 37772.008 & 1 & 37772.008 & $9.382 \mathrm{E} 4$ & .000 & .999 \\
\hline Proficiency & 91.875 & 1 & 91.875 & $2.282 \mathrm{E} 2$ & .000 & .663 \\
\hline Methodology & 267.008 & 1 & 267.008 & $6.632 \mathrm{E} 2$ & .000 & .851 \\
\hline Proficiency $*$ Methodology & 11.408 & 1 & 11.408 & 28.338 & .000 & .196 \\
\hline Error & 46.700 & 116 & .403 & & & \\
\hline Total & 38189.000 & 120 & & & & \\
\hline Corrected Total & 416.992 & 119 & & & & \\
\hline
\end{tabular}

a. R Squared $=.888$ (Adjusted R Squared $=.885$ )

As it is seen in this table, the significant value between the proficiency levels (upper and lower-intermediate) and two methods (the keyword and word-list method) is 0.00 which is less than $0.05(0.00<0.05)$. It means that there is a statistically significant difference between the students in the keyword method and those in the word-list method group.

This shows that using the keyword method instruction for the upper-intermediate level students is superior to using the word-list method instruction. In addition, using the keyword method instruction for the lower-intermediate level students is superior to using the word-list method instruction.

\section{DisCUSSION AND CONCLUSION}

The results of this study showed that there is a significant difference between the performances of the keyword method group and the word-list method group across different proficiency levels. 
In the upper-intermediate level group, the participants who received the keyword method instruction outperformed the participants who received the word-list method. In the case of the lower-intermediate level group, the participants in the keyword method group had better performance than those in the word-list method one.

In addition, irrespective of the proficiency level of the student, all of the students in the keyword method group had reached to the higher level of knowledge and scores than the students in the word-list method group. It can be concluded from this study that the keyword method instruction enhances ESP vocabulary learning. That is to say, the keyword method instruction has more effective influences on the knowledge of the ESP vocabularies of the students than the word-list method have. It means that the keyword method instruction as a vocabulary learning strategy enhances the ESP students' vocabulary learning.

The results of the study are in accordance with a number of previous studies (Amiryousefi \& Ketabi, 2011; Atay \& Ozbulgan, 2007; Atkinson \& Rough, 1975; Baleghizadeh \& Ashoori, 2010, Jenpattarakul, 2012; Tabatabaei \& Hejazi, 2011) who believed in the superiority of the keyword method instruction to the word-lists method one in the learning of ESP vocabularies.

The results of this study are not in line with those of Atkinson and Rough (1975) who stated that the keyword method is most useful for the beginners. As the participants of this study were in the intermediate level and their average age was twenty-one, the application and usage of the keyword method instruction had a significant effect on the improvement of their ESP vocabularies. In turn, this study confirmed the results of Taguchi (2006) who found that the keyword method facilitate foreign language vocabulary learning of experienced and older learners.

As the context of this study was the ESP vocabularies and all of the related ESP vocabularies, in this study, were abstract, the results of this study are in accordance with those of the Rashidi and Sajjadi (2010) who stated that the keyword method facilitates learning of the abstract words. Moreover, the results are in line with those of Hauptmann (2004) who believed that the keyword method is good for learning both abstract and concrete words. However, it should not be ignored that in using the keyword for the ESP vocabularies that are abstract, the mental images should be concrete to have better effect.

As the keyword method can enhance the imagination and creativity of the ESP students and helps in connecting the mental image of a word into the meaning of that word, this process leads to meaningful learning and the degree of the rote learning can be decreased (Jenpattarakul, 2012). As the results show, it completely decreased the students' feeling of stress and they enjoyed the learning process. But making a mental image for some of the ESP words is difficult for the students and needs more time.

On the other hand, learning through word-list method needs more rehearsal and is more time consuming in comparison to the keyword method. In addition, the students stated that learning ESP vocabularies through the word-list method is boring because they needed to repeat a large amount of words without any association between the ESP words and their meanings. In spite of the time that students dedicate to the learning the ESP words through the word-list method, they may gain nothing because they forget most of the ESP words after a few days.

Amiryousefi and Ketabi (2011) believe that the keyword method improves vocabulary learning and this method is considered as a useful way for enhancing vocabulary learning and retention. Therefore, if the time of the class allow, it is better to incorporate the keyword method to the students' regular language learning schedule. In order to have better results, it is better to complement the keyword method with word-list method. As Amiryousefi and Ketabi (2011) stated memory techniques should not replace other approaches of vocabulary learning, but should complement them.

Learners prefer to work on the vocabulary-learning methods, which they can learn the ESP vocabularies fast and lead them to the best results. If the students would not be aware of all the methods and strategies of learning vocabularies, they may try the methods, which take them more time and do not have the students' desired outcome. Importantly, their motivation for learning ESP vocabularies will be decrease and in turn, they receive backfire results. In this regard, they should be aware of all the possible vocabulary-learning methods. Therefore, this study may have some insights for the students that the keyword method is not limited to one or two fields of study and is not intended for the special ages or proficiency levels.

In addition, teachers should consider all the determining factors of the students, such as age, proficiency level, the learning styles and preferences as well as the background knowledge of students, and review all the existed vocabularylearning strategies and methods and continue to try the new vocabulary learning methods which are more fit to their students. It means that they should provide teaching conditions that students try the possible vocabulary-learning methods.

Since all the learners are different from each other and consequently their learning styles are different, teachers should encourage students to get behind the words and look for the mental images that the words carry to internalize the meaning of the words effectively rather than remember them for a short time.

With the help of the result of this study, syllabus designers can allocate more space in their course books to the mental images of the lexical items. They also can design special vocabulary course books to teach vocabulary to learners through mental images. Besides, the results of this study can have some insights for the researchers and help them to examine other dimensions of this research. 


\section{REFERENCES}

[1] Akbari, Z. (2011). Vocabulary comprehension and learning in an ESP context: Strategy use and knowledge sources. Asian ESP Journal, 7(2), 5-27.

[2] Amiryousefi, M. \& Ketabi S. (2011). Mnemonic Instruction: A way to boost vocabulary learning and recall. Journal of Language Teaching and Research, 2 (1), 178-182.

[3] Ashoori Tootkaboni, A. (2012). Recall of foreign-language vocabulary: Effects of keyword, context and wordlist instructional strategies on long-term vocabulary recall of EFL learners. Journal of Theory and Practice in Education, 8(1), 54-71.

[4] Atay, D. \& Ozbulgan, C. (2007). Memory strategy instruction, contextual learning and ESP vocabulary recall. Journal of English for Specific Purposes, 26, 39-51.

[5] Atkinson, R. C. \& Raugh, M. R. (1975). An application of the mnemonic keyword method to the acquisition of Russian vocabulary. Journal of Experimental Psychology: Human Learning and Memory, 104 (2), 126-133.

[6] Baleghizadeh, S. \& Ashoori, A. (2010). The effect of keyword and word-list methods on immediate vocabulary retention of EFL learners. Pakistan Journal of Social Sciences (PJSS), 30 (2), 251-261.

[7] Baleghizadeh, S. \& Ashoori A. (2011). The impact of two instructional techniques on EFL learners' vocabulary knowledge: Flash cards versus word-Lists. MEXTESOL Journal, 35 (2), 1-9.

[8] Chung T. M. \& Nation P. (2004). Identifying technical vocabulary. An International Journal of Educational Technology and Applied Linguistics. Journal of System, 32, 251-263.

[9] Hauptmann, J. (2004). The Effect of the Integrated Keyword Method on Vocabulary Retention and Motivation. PHD thesis. University of Leicester. School of Education. Retrieved Oct. 12, 2012 from http: //www. Keywordmethod.de/own_docs/pdf.

[10] Hayati Samian, S. \& Tavakoli, M. (2012). The relationship between Iranian EFL learners rote learning strategy use and their level of proficiency. Journal of Language Teaching and Research, 3 (4), 625-631.

[11] Higbee, K. L. (2007). Your memory: how it works and how to improve it. Retrieved Oct. 18 , 2012 from http://www.marshallcf.com/assets/book_review/

[12] Jenpattarakul, W. (2012). The impact of keyword technique on the students' vocabulary retention ability in an EFL class. Mediterranean Journal of Social Sciences, 3 (3), 565-573.

[13] Khosravizadeh, P. \& Gerami, S. (2011). Word-list recall in youngsters and older adults. Journal of Broad Research in Artificial Intelligence and Neuroscience (BRAIN), 2 (1), 5-10.

[14] Lin, F. Y. \& Cheng, C.K. (2008). The combined effects of the keyword method and phonics instruction on fifth graders' English vocabulary learning in Taiwan. Journal of English Teaching \& Learning, 32 (3), 71-114.

[15] Rashidi, N. \& Sajjadi, M. (2010). The effect of time intervals on the keyword mnemonic technique used in teaching vocabulary to Iranian female EFL learners. Iranian EFL Journal, 6 (3), 45-69.

[16] Richmond, A. S., Cummings, R. \& Klapp, M. (2008). Transfer of the method of loci, peg word, and keyword mnemonics in the eighth grade classroom. Journal of Northern Rocky Mountain Educational Research Association. 21(2), 1-13.

[17] Schmitt, N. (2007). International handbook of English language teaching. In J. Cummins \& C. Davison (Eds.), Current perspectives on vocabulary teaching and learning, 15, 827-841. Springer International Handbook of English Language Teaching.

[18] Tabatabaei, O. \& Hossainzadeh Hejazi, N. (2011). Gender differences in vocabulary instruction using keyword method (Linguistic Mnemonics). Journal of Canadian Social Science, 7 (5), 198-204.

[19] Tabatabaei, O. \& Hossainzadeh Hejazi, N. (2011). Using similarity in form between L1-L2 vocabulary items (keyword method/linguistic mnemonics) in L2 vocabulary. Journal of International Conference on Languages, Literature and Linguistics, 26, 270-275.

[20] Taguchi, K. (2006). Should the keyword method be introduced in tertiary foreign language classrooms? Electronic Journal of Foreign Language Teaching, 3 (1), 22-38.

[21] Yang, W. D. \& Dai, W. P. (2012). Vocabulary memorizing strategies by Chinese university students. Journal of International Education Studies, 5 (1), 208-215.

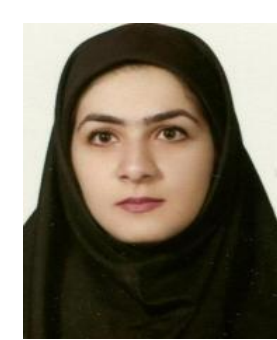

Ana Piribabadi, was born in Tehran on 1981, received her BA degree in English translation in 2003 from Takestan Islamic Azad University, Iran. She received her MA degree from Takestan Islamic Azad University in 2013. She has been teaching English courses for six years at several institutes. Her research interests are in vocabulary learning, foreign language teaching and learning, reading comprehension, and ESP.

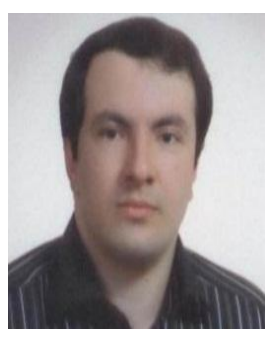

Ramin Rahmany is a Ph.D. holder of teaching English as a foreign language from Tehran University, Iran. Currently, he is an assistant professor in Azad University of Takestan, Iran. His major interests are language and acquisition, computer assisted language learning, and psycholinguistics. He has taught several courses at university like Language methodology and discourse analysis. He has published several articles in language learning acquisitions e.g. Acquisition of English Relative Clauses by Persian EFL Learners published by Journal of Language and Linguistic Studies in October 2009. 